\title{
STUDI PRIORITAS PEMELIHARAAN JALAN DI KOTA MAKASSAR
} (STUDY OF ROAD MAINTENANCE PRIORITIES IN CITY OF MAKASSAR)

\author{
St. Maryam H ${ }^{1}$, Lambang Basri Said ${ }^{2}$, Tutun Banyuwiguna ${ }^{3}$ \\ ${ }^{1}$ Dosen Jurusan Teknik Sipil Universitas Muslim Indonesia (UMI) \\ Jalan Urip Sumoharjo No.225 Makassar, Telp. 454534 \\ ${ }^{2}$ Dosen Jurusan Teknik Sipil Universitas Muslim Indonesia (UMI) \\ Jalan Urip Sumoharjo No.225 Makassar, Telp. 454534 \\ ${ }^{3}$ Staff Dinas Pekerjaan Umum Kota Makassar \\ JL.Urip Sumihardjo No.8 Makassar, toenbayu@gmail.com
}

\begin{abstract}
Abstrak
Menyikapi permasalahan-permasalahan yang ada, maka salah satu alternatif dalam penanganan proyek jalan dengan anggaran yang terbatas adalah penanganan jalan berdasarkan skala prioritas. Penanganan jalan difokuskan pada pengembangan wilayah-wilayah potensial yang diharapkan dapat memberikan kontribusi secara langsung bagi masyarakat dan pembangunan daerah secara makro. Disamping itu pula, penanganan jalan berdasarkan skala prioritas dengan kriteria penanganan yang tepat mampu memberikan hasil yang lebih baik, efesien dan efektif, dengan pertimbangan bahwa ruas jalan tersebut perlu ditingkatkan selain karena kerusakan jalan juga memiliki peranan dan manfaat lain dalam rangka peningkatan taraf sosial ekonomi masyarakat yang mendiami wilayah tersebut., Penelitian ini merupakan penelitian yang bersifat deskriptif kualitatif dan kuantitatif. Dengan demikian akan digambarkan kondisi objek penelitian dan hasil penelitian secara kuantitas dan kualitas berdasarkan tabulasi. Adapun metode survei dilakukan dengan pembagian kuesioner kepada responden dan pengamatan langsung di lokasi penelitian. Hasil penelitian menunjukkan kriteria-kriteria yang menjadi pertimbangan dalam penanganan jalan; (1) aksesibilitas, (2) mobilitas, (3) kerusakan jalan dan (4) fungsi akses jalan. Data ruas jalan 2018 yang dtiinjau berdasarkan kriteria aksessibilitas, mobilitas dan kerusakan jalan maka yang menjadi prioritas penanganan jalan di Kecamatan Ujung Pandang Kota Makassar berturut-turut adalah (1) Jalan Balaikota; (2) Jalan H.Bau; (3) Jalan Ince Nurdin.
\end{abstract}

Kata kunci : Penaganan Jalan, Pemeliharaan, Aksessibilitas, Mobilitas, Kerusakan Jalan

\section{PENDAHULUAN}

\subsection{Latar Belakang}

Transportasi mempunyai peran yang sangat penting dalam pengembangan suatu wilayah, yaitu untuk memudahkan interaksi antar wilayah. Kemudahan interaksi antar wilayah akan membawa manfaat ekonomi dan sosial, jaringan transportasi/jalan yang baik akan merangsang bangkitnya pergerakan penduduk untuk melakukan kegiatan sosial ekonomi. Hal tersebut menunjukkan bahwa pembangunan jaringan transportasi/jalan mempunyai hubungan timbal balik dengan perekonomian suatu daerah dalam menunjang pertumbuhan dan perkembangan kawasan perkotaan dan perdesaan. Pengembangan sistem transportasi di Kota Makassar diarahkan untuk meningkatkan aksesibilitas antar wilayah di dalam Kota Makassar dan aksesibilitas antara wilayah kabupaten/kota yang ada di sekitarnya.

Menyikapi permasalahan-permasalahan yang ada, maka salah satu alternatif dalam penanganan proyek jalan dengan anggaran yang terbatas adalah penanganan jalan berdasarkan skala prioritas. Penanganan jalan yang berdasarkan skala prioritas ini difokuskan pada pengembangan wilayah-wilayah potensial yang diharapkan dapat memberikan kontribusi secara 
langsung bagi masyarakat dan pembangunan daerah secara makro. Disamping itu pula, penanganan jalan berdasarkan skala prioritas dengan kriteria penanganan yang tepat mampu memberikan hasil yang lebih baik, efesien dan efektif, dengan pertimbangan bahwa ruas jalan tersebut perlu ditingkatkan selain karena kerusakan jalan juga memiliki peranan dan manfaat lain dalam rangka peningkatan taraf sosial ekonomi masyarakat yang mendiami wilayah tersebut.

\subsection{Rumusan Masalah}

Rumusan masalah yang akan dikaji dari penelitian ini adalah :

1. Bagaimana kriteria dalam penentuan prioritas penanganan jalan di Kecamatan Ujung Pandang Kota Makassar?

2. Bagaimana urutan prioritas penanganan jalan di Kecamatan Ujung Pandang Kota Makassar ditinjau terhadap aspek akses jalan, aksessibilitas, mobilitas dan kerusakan jalan?

\subsection{Tujuan Penelitian}

Tujuan yang ingin dicapai dari penelitian ini adalah :

1. Menganalisis kriteria dalam penentuan prioritas penanganan jalan di Kecamatan Ujung Pandang Kota Makassar

2. Menganalisis prioritas penanganan jalan di Kecamatan Ujung Pandang Kota Makassar ditinjau terhadap aspek Fungsi akses jalan, aksessibilitas, mobilitas dan kerusakan jalan

\section{METODE PENELITIAN}

\subsection{Jenis Penelitian dan Metode Survei}

Penelitian ini merupakan penelitian yang bersifat deskriptif kualitatif dan kuantitatif. Dengan demikian akan digambarkan kondisi objek penelitian dan hasil penelitian secara kuantitas dan kualitas berdasarkan tabulasi. Adapun metode survei dilakukan dengan pembagian kuesioner kepada responden dan pengamatan langsung di lokasi penelitian.

\subsection{Waktu dan Lokasi Penelitian}

Penelitian ini dilaksanakan di Kecamatan Ujung Pandang Kota Makassar Provinsi Sulawesi Selatan. Dalam penelitian ini dilakukan untuk menetapkan prioritas penanganan jalan ditinjau terhadap aspek akses jalan, aksessibilitas, mobilitas dan kerusakan jalan

Adapun waktu penelitian ini telah dilakukan awal Oktober 2018 hingga November 2018.

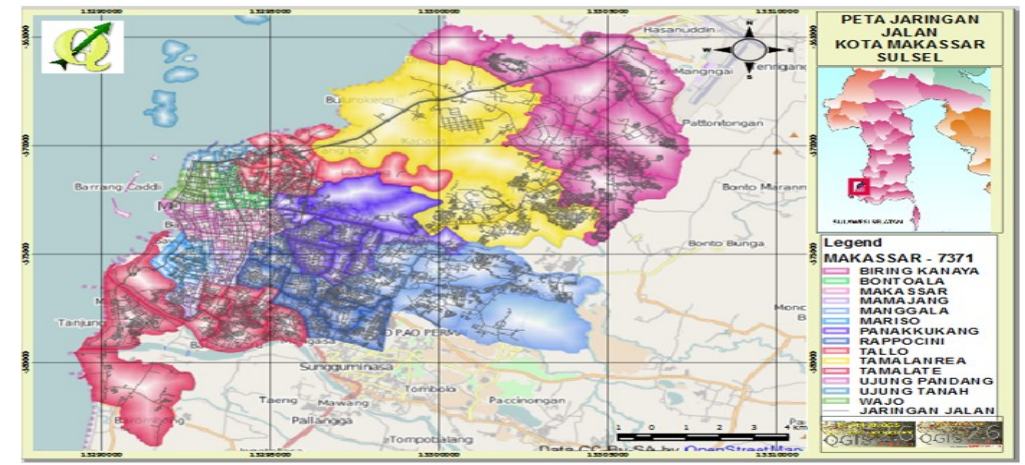

Gambar 4. Peta Ruas Jalan Kota Makassar

\subsection{Sasaran Penelitian}


Sasaran penelitian adalah ruas jalan Kecamatan Ujung Pandang di Kota Makassar sedangkan responden adalah stakeholder yang memiliki kompetensi dalam penyelenggaraan jalan.

\subsection{Teknik Pengumpulan Data}

Penelitian ini menuntut sejumlah data yang diperoleh melalui data primer seperti wawancara atau kuesioner maupun data sekunder berupa informasi dari instansi terkait. Adapun data yang dibutuhkan antara lain data primer berupa pendapat/persepsi responden terhadap kriteria dan sub kriteria yang diusulkan, dan data sekunder berupa data ruas jalan, data produk unggulan, data mengenai potensi wilayah, data mengenai Rencana Tata Ruang Wilayah, data tentang kondisi geografis, luas dan jumlah penduduk.

\section{Data Primer}

Data primer merupakan data yang diperoleh langsung yang berasal dari stakeholder yang memiliki kompetensi dan terkait penyelenggaraan jalan guna penetapan kriteria penanganan jalan, pada tingkat perencana dan pelaksana saja. Hasil dari kuesioner ini adalah informasi bobot relatif antar kriteria agar diperoleh perbandingan bobot antar keduanya yang akan menentukan tingkat kepentingan antar variabel kriteria yang dipertimbangkan. Data pembobotan ini diperoleh dengan menganalisis hasil survei, dimana stakeholder yang dipilih dihadapkan pada pertanyaan yang mengarah kepada perbandingan tingkat kepentingan antar kriteria.

Adapun stakeholder pada tingkat Pelaksana adalah:

1. Kepala Dinas Pekerjaan Umum Kota Makassar

2. Kepala Bidang Bina Marga Dinas Pekerjaan Umum Kota Makassar

3. Kepala Seksi Pembangunan dan Peningkatan Jalan Dinas PU Kota Makassar

Sedangkan stakeholder pada tingkat Perencana adalah:

1. Kepala BAPPEDA Kota Makassar

2. Kepala Bidang Perencanaan Wilayah BAPPEDA Kota Makassar

3. Kepala Bidang Ekonomi dan Sosbud BAPPEDA Kota Makassar

4. Kepala Sub. Bidang Prasarana Wilayah BAPPEDA Kota Makassar

\section{Data Sekunder}

Data sekunder merupakan data yang telah tersedia di beberapa sumber instansi-instansi terkait yang dibutuhkan dalam mendukung penelitian. Data sekunder yang dibutuhkan, antara lain :

a. Data ruas jalan Kecamatan Ujung Pandang diperoleh dari Dinas PU Kota Makassar.

b. Data tentang kondisi geografis, luas dan jumlah penduduk diperoleh dari BPS Kota Makassar.

\subsection{Metode Analisis}

\section{Analisis Hirarki Proses}

Penetapan kriteria penanganan jalan dilakukan dengan Analisis Multi Kriteria menggunakan Metode Proses Hirarki Analitik (Analytical Hierarchy Process) atau disingkat AHP. Langkah-langkahnya sebagai berikut: pembobotan kriteria, penghitungan rasio konsistensi, pembobotan total kriteria.

\section{a. Pembobotan Kriteria}

Pembobotan kriteria dilakukan dengan memperhatikan rekapitulasi data kuesioner masing-masing responden/stakeholder dengan cara menghitung jumlah pendapat responden/stakeholder. Bila penilaian lebih dari satu berarti elemen pembanding memiliki arti lebih penting dari elemen yang dibandingkan. Jika penilaian sama dengan satu berarti bahwa elemen pembanding dengan elemen yang dibandingkan memiliki arti sama penting, dan bila nilai berupa pecahan berarti elemen yang dibandingkan memiliki arti lebih penting dari elemen pembanding.

\section{b. Penghitungan Rasio Konsistensi}


Penghitungan rasio konsistensi diperlukan apakah perbandingan berpasangan telah dilakukan dengan konsisten atau tidak. Beberapa variabel yang digunakan dalam penghitungan konsistensi ini antara lain, yaitu: nilai eigen, ukuran matriks random yang diperoleh dari tabel 7. Seharusnya nilai dari rasio konsistensi (CR) tidak lebih dari 0,10 jika penilaian kriteria telah dilakukan dengan konsisten.

\section{c. Pembobotan Total Kriteria}

Nilai pengolahan data dari seluruh kriteria merupakan bobot lokal rata-rata dari seluruh stakeholder dari semua kriteria dengan rasio konsistensi (CR) lebih kecil dari 0,10.

\subsection{Definisi Operasional}

Definisi operasional dimaksudkan untuk memberikan pengertian dan pemahaman yang jelas terhadap variabel dan cara penilaian dalam penelitian ini.

\section{Analisis Hirarki Proses}

Analisis Multi Kriteria ini dikaji dengan menggunakan Metode Analytical Hierarchy Process (AHP) yang dikembangkan oleh Thomas L Saaty, merupakan salah satu pendekatan perencanaan yang memungkinkan diakomodasikannya sejumlah kepentingan dari sejumlah kriteria dalam proses pengambilan keputusan (Tamin, 2002).

Mudahnya suatu lokasi dihubungkan dengan lokasi lainnya lewat jaringan transportasi yang ada, berupa prasarana jalan dan alat angkutyang bergerak di atasnya. Dengan kata lain, suatu ukuran dan kemudahan kenyamanan mengenai cara lokasi petak (tata) guna lahan yang saling berpencar, dapat berinteraksi (berhubungan satu sama lain. Dan mudah atau sulitnya lokasi-lokasi tersebut dicapai melalui sistem jaringan transportasinya, merupakan hal yang sangat subyektif, kualitatif, dan relative sifatnya (Tamin, O.Z, 1997)

Penentuan indeks aksesibilitas suatu wilayah berdasarkan Standar Pelayanan Minimum (SPM) yang dikeluarkan melalui Keputusan Menteri Kimpraswil No. 534/KPTSM/2001.

Indeks aksesibilitas dapat dinyatakan dalam bentuk variabel peningkatan indeks aksesibilitas yaitu :

$$
\left(\frac{\text { Panjang Jalan disuatuwilayah }(\mathrm{km})}{\text { Luas wilayahDaratan }\left(\mathrm{km}^{2}\right)}\right)
$$

\section{Aspek dan Kriteria Penelitian}

a. Aspek Teknis Tingkat Kerusakan Jalan (X3)

Kerusakan jalan yang dimaksudkan adalah kerusakan lapis permukaan yang menggambarkan kondisi ruas-ruas jalan yang ditinjau. Adapun variabel yang digunakan pada kriteria kerusakan jalan ada tiga yaitu: rusak berat, rusak ringan, dan baik. Tingkat kerusakan berdasarkan SK Menteri PU No: 77/KPTS/Db/1990 Tentang Perencanaan dan Penyusunan Program Jalan Kabupaten.

b. Aspek Aksesibilitas (X1)

Jumlah dan Penyebaran Penduduk

c. Aspek Mobilitas (X2)

Kriteria ini adalah kriteria yang terkait dengan ketersediaan prasarana transportasi yang dapat menampung mobilitas masyarakat di suatu wilayah. Kriteria Mobilitas dapat dinyatakan dalam bentuk variabel peningkatan indeks Mobilitas yaitu :

$$
\left(\frac{\text { Panjang Jalandisuatuwilayah }(\mathrm{km})}{1000 \text { penduduk(jiwa) }}\right)
$$

Penentuan indeks mobilitas suatu wilayah berdasarkan Standar Pelayanan Minimum (SPM) yang dikeluarkan melalui Keputusan-Menteri Kimpraswil No. 534/KPTSM/2001.

d. Fungsi Jalan $(\mathbf{X})$

Fungsi akses jalan $\quad=$ Kota $(0,25)$, Provinsi $(0,75)$, Nasional $(1)$ 


\begin{tabular}{|c|c|c|}
\hline Kriteria & Tingkat Kepentingan & Nilai Fungsi Keanggotaan \\
\hline Nasional & Sangat Penting & $0.75,1, \mathbf{1}$ \\
\hline Provinsi & Penting & $0.5, \mathbf{0 . 7 5}, 1$ \\
\hline Kota & Cukup Penting & $\mathbf{0 . 2 5}, 0.5,0.75$ \\
\hline
\end{tabular}

\section{ANALISIS DATA}

\subsection{Analisis Hirarki Proses}

Pembobotan kriteria merupakan tahap awal dari analisis dengan metode AHP yang dilakukan dengan cara menyebarkan sejumlah kuesioner ke masing-masing instansi yang berkompeten. Responden dari instansi baik perencana maupun pelaksana berfungsi sebagai stakeholder yang memberikan penilaian tentang tingkat kepentingan masing-masing kriteria yang digunakan dalam penelitian ini.

Berikut ini akan ditampilkan urutan analisis berdasarkan data yang diperoleh dari responden stakeholder 1 dalam penanganan jalan di lokasi penelitian. Adapun hasil analisis terhadap data yang diberikan oleh stakeholder lainnya akan disajikan dalam bentuk tabel (pada halaman lampiran).

Langkah 1. Penyusunan matriks berpasangan

Tabel 15. Matriks Perbandingan Berpasangan Kriteria (stakeholder 1)

\begin{tabular}{|l|c|c|c|}
\hline Kriteria & Aksesibiltas & Mobilitas & $\begin{array}{c}\text { Kerusakan } \\
\text { jalan }\end{array}$ \\
\hline Aksesibiltas & 1,000 & 1,000 & 7,000 \\
\hline Mobilitas & 1,000 & 1,000 & 5,000 \\
\hline Kerusakan jalan & 0,143 & 0,200 & 1,000 \\
\hline
\end{tabular}

Sumber : Hasil analisis

Langkah 2. Menghitung bobot masing-masing kriteria

Data yang ada pada matriks diatas (tabel 15) merupakan hasil penilaian mengenai perbandingan berpasangan responden, selanjutnya dinormalisasi menjadi bobot masing-masing kriteria dengan cara mengalikan setiap nilai elemen matriks perbandingan berpasangan yang berada pada baris yang sama, kemudian perkalian tersebut dipangkatkan dengan jumlah kriteria seperti pada persamaan (1) yaitu:

$$
\begin{aligned}
& \mathrm{Wi}=\mathrm{n} \sqrt{\left(a_{11} x a_{12} x a_{13} x \ldots \ldots \ldots a_{i j}\right.} \\
& \mathrm{Wi}=3 \sqrt{(1,000 \times 1.000 \times 7.000}=1,9129
\end{aligned}
$$

berikut:

Dengan cara yang sama diperoleh masing-masing nilai Wi pada tiap baris sebagai

$$
\begin{aligned}
& \mathrm{W}_{1}=1,9129 \\
& \mathrm{~W}_{2}=1,7110 \\
& \mathrm{~W}_{3}=0,3058 \\
& \hline
\end{aligned}
$$

$\Sigma \mathrm{Wi}=3,9297$ 
Sedangkan untuk memperoleh bobot lokal setiap kriteria diperoleh dengan menggunakan persamaan $(2) \mathrm{Xi}=(\mathrm{Wi} / \Sigma \mathrm{Wi})$ berikut :

Dari persamaan tersebut diatas peroleh bobot lokal untuk masing-masing kriteria sebagai

a. Bobot kriteria Aksesibilitas $\left(\mathrm{X}_{1}\right) \quad=0,4868$

b. Bobot kriteria Mobilitas $\left(X_{2}\right) \quad=0,4354$

c. Bobot kriteria Kerusakan Jalan $\left(\mathrm{X}_{3}\right)=0,0778$

Langkah 3. Menghitung Nilai Eigen Maksimum

Setelah diperoleh bobot lokal kriteria, selanjutnya data yang ada pada matriks perbandingan berpasangan dikalikan dengan bobot lokal yang diperoleh. Hasil perkalian tersebut dijumlahkan, sehingga diperoleh nilai egienvalue maksimum dari persamaan (3) sebagai berikut:

$\lambda_{\text {maks }}=\Sigma \mathrm{a}_{\mathrm{ij}} \mathrm{Xi}$

$\begin{array}{lll}1,000 & 1,000 & 7,000 \\ 1,000 & 1,000 & 5,000 \\ 0,143 & 0,200 & 1,000\end{array}|\times| \begin{aligned} & 0,4868 \\ & 0,4354 \\ & 0,0778\end{aligned}|=| \begin{gathered}1,4668 \\ 1,3112 \\ 0,2345\end{gathered}$

Egienvalue maksimum adalah:

$$
\begin{aligned}
\lambda_{\text {maks }} & =\Sigma \mathrm{a}_{\mathrm{ij}} \mathrm{Xi} \\
& =1,4668+1,3112+0,2345 \\
& =3,0125
\end{aligned}
$$

Langkah 4. Menghitung Indeks Konsistensi

Indeks konsistensi diperoleh dengan menggunakan persamaan (4) sebagai berikut:

$C I=\left(\lambda_{\text {maks }}-n\right) /(n-1)=3,0125-3 /(3-1)=0,00625$

Langkah 5. Menghitung Rasio Konsistensi

Rasio konsistensi merupakan parameter yang digunakan untuk memeriksa apakah perbandingan .berpasangan telah dilakukan dengan konsekuen. Nilai rasio konsistensi dianggap memenuhi syarat apabila $<0,10$.

Nilai rasio konsistensi diperoleh dari perbandingan nilai indeks konsistensi (langkah 4) dengan indeks random (tabel 6). Dari Tabel diperoleh bahwa untuk $\mathrm{n}=3$, maka indeks random (Rl) $=0,58$. Dengan demikian rasio konsistensi stakeholder 1 adalah:

$\mathrm{CR}=\mathrm{CI} / \mathrm{RI}=0,00625 / 0,58$

$=0,0108<0,10$ (memenuhi syarat)

Dengan langkah-langkah seperti yang dilakukan terhadap kuesioner yang diisi oleh stakeholder 1, kuesioner untuk seluruh stakeholders dianalisis dan bobot masing-masing kriteria berdasarkan penilaian dari setiap stakeholder yang dirangkum pada tabel berikut ini.

Tabel 16. Bobot Lokal Rata-rata Kriteria dari SeluruhStakeholder

\begin{tabular}{|c|c|c|c|c|c|c|c|}
\hline Stakeholder & Stake. & Stake. & Stake. & Stake. & Stake. & Stake. & Stake. \\
\cline { 1 - 6 } Kriteria & $(1)$ & $(2)$ & $(3)$ & $(4)$ & $(5)$ & $(6)$ & $(7)$ \\
\hline
\end{tabular}




\begin{tabular}{|l|c|c|c|c|c|c|c|}
\hline Aksesibiltas & 0,4868 & 0,6587 & 0,6371 & 0,4054 & 0,4666 & 0,7306 & 0,3333 \\
\hline Mobilitas & 0,4354 & 0,1851 & 0,2582 & 0,4807 & 0,4666 & 0,1884 & 0,3333 \\
\hline Kerusakan jalan & 0,0778 & 0,1562 & 0,1047 & 0,1139 & 0,0667 & 0,0810 & 0,3333 \\
\hline
\end{tabular}

Sumber : Hasil analisis

Berdasarkan tabel 16 secara umum dari seluruh stakeholder menunjukkan bahwa kriteria dengan bobot yang tertinggi adalah aksesibiltas (3.662). Dengan persepsi tersebut sebagian besar dari stakeholder beranggapan bahwa aksesibilitas jalan lebih penting dan perlu adanya penanganan jalan sehingga dapat meningkatkan aksesibilitas dan mobilitas antar wilayah kecamatan dalam memenuhi kebutuhan ekonomi dan sosial.

Dari hasil pembobotan kriteria setiap responden maka dapat diperoleh bobot kriteria secara keseluruhan dengan cara membagi jumlah setiap kriteria dengan jumlah stakeholder. Hasil pembobotan rata-rata secara keseluruhan kelompok stakeholder terdapat pada tabel berikut.

Tabel 17. Persentase bobot kriteria penanganan jalan

\begin{tabular}{|c|l|c|}
\hline No. & Kriteria & Bobot $(\%)$ \\
\hline 1 & Aksesibiltas & 0,531 \\
\hline 2 & Mobilitas & 0,336 \\
\hline 3 & Kerusakan Jalan & 0,133 \\
\hline
\end{tabular}

Sumber : Hasil analisis

Dari tabel 17 dapat di lihat urutan peringkat bobot kriteria yaitu aksesibilitas dengan bobot 0,531, mobilitas 0,336 dan kerusakan jalan 0,133.

Kondisi tersebut sangat berbeda antara persepsi antara kelompok stakeholder dengan kebijakan sektor jalan yang ada pada tahun 2017 menunjukkan bahwa kebijakan dalam sektor jalan masih di dominasi oleh kebijakan penambahan aset jalan atau penambahan ketersediaan prasarana jalan dalam bentuk program pembangunan jalan dan kurang memprioritaskan pemeliharaan rutin serta pemeliharaan berkala.

\subsection{Penetapan Prioritas Penanganan Jalan}

Berdasarkan hasil analisis sebelumnya, maka dapat ditetapkan prioritas penanganan jalan. Persamaan untuk menentukan prioritas penanganan jalan ini adalah hasil analisis hirarki proses.Persamaan tersebut sebagai berikut:

$Y=X+(a 1 x$ bobot $X 1)+(a 2 x$ bobot $X 2)+(a 3 x$ bobot $X 3)+(a n \times b n)$

Dimana :

$\mathrm{X}=$ Fungsi akses jalan

fungsi akses jalan $=\operatorname{Kota}(0,25)$, Provinsi $(0,75)$, Nasional (1)

\begin{tabular}{|c|c|c|}
\hline Kriteria & Tingkat Kepentingan & Nilai Fungsi Keanggotaan \\
\hline Nasional & Sangat Penting & $0.75,1, \mathbf{1}$ \\
\hline Provinsi & Penting & $0.5, \mathbf{0 . 7 5}, 1$ \\
\hline
\end{tabular}




\begin{tabular}{|l|l|l|}
\hline Kota & Cukup Penting & $\mathbf{0 . 2 5}, 0.5,0.75$ \\
\hline
\end{tabular}

$\mathrm{X} 1=$ Aksesibilitas

$\mathrm{X} 2=$ Mobilitas

$\mathrm{X} 3$ = Kerusakan Jalan

Dari persamaan (6) di atas, score untuk Jalan sultan Hasanuddin adalah sebagai berikut:

Score $=0.25+(0,531 * 10.8715)+(0,336 * 0,001)+(0,133 * 0,042)$

Score $=3.84$

Bobot yang diperoleh ruas jalan sultan Hasanuddin menunjukkan bahwa ruas jalan tersebut menempati prioritas sembilan untuk penanganan jalan. Hal ini disebabkan pada ruas jalan tersebut kondisi kerusakan jalan sebagiannya rusak.

Tabel 19. Prioritas penanganan ruas jalan di Kecamatan Ujung Pandang

\begin{tabular}{|c|c|c|c|}
\hline $\begin{array}{c}\text { Kode ruas } \\
\text { jalan }\end{array}$ & Kecamatan/nama ruas jalan & Bobot & Prioritas \\
\hline 4 & Sultan Hasanuddin & 3.84 & 9 \\
\hline 6 & H. Bau & 7.98 & 2 \\
\hline 8 & Balaikota & 10.30 & 1 \\
\hline 18 & Emmy Saelan & 7.70 & 4 \\
\hline 20 & Karunrung & 7.21 & 8 \\
\hline 22 & G. Klabat & 7.31 & 7 \\
\hline 23 & Chairil Anwar & 7.67 & 5 \\
\hline 36 & Sawerigading & 7.66 & 6 \\
\hline 38 & Jambu & 2.483 & 18 \\
\hline 40 & Mochtar Lutfi & 2.98 & 11 \\
\hline 41 & Dr.Sutomo & 3.62 & 10 \\
\hline 57 & Rambutan & 2.484 & 17 \\
\hline 59 & S. Cendrana & 2.83 & 12 \\
\hline 61 & Ince Nurdin & 7.83 & 3 \\
\hline 63 & Ina Saudari & 2.81 & 13 \\
\hline 65 & Bonto Marannu & 2.52 & 17 \\
\hline 76 & S.Klara & 2.72 & 14 \\
\hline 77 & S.Tallo & 2.55 & 16 \\
\hline 78 & S.Musi & 2.44 & 19 \\
\hline 79 & S.Digul & 2.40 & 20 \\
\hline 85 & G. Kairo & 2.65 & 15 \\
\hline
\end{tabular}

Sumber : Hasil analisis

Untuk susunan prioritas dan hasil penghitungan bobot secara rinci dapat dilihat pada Lampiran.

\section{KESIMPULAN}

Dari hasil penelitian dan pembahasan terhadap prioritas penanganan jalan di Kota Makassar, maka dapat disimpulkan beberapa haI sebagai berikut:

1. Hasil penelitian menunjukkan kriteria-kriteria yang menjadi pertimbangan dalam penanganan jalan; (1) aksesibilitas, (2) mobilitas, (3) kerusakan jalan dan Fungsi akses jalan (4)

2. Data ruas jalan 2018 yang dtiinjau berdasarkan kriteria aksessibilitas, mobilitas dan kerusakan jalan maka yang menjadi prioritas penanganan jalan di Kecamatan Ujung Pandang Kota Makassar berturut-turut adalah (1) Jalan Balaikota; (2) Jalan H.Bau; (3) Jalan Ince Nurdin. 


\section{SARAN}

Dari hasil analisis dan pembahasan serta kesimpulan yang diperoleh, beberapa saran yang dapat dikemukakan dari hasil penelitian ini adalah:

1. Agar Dinas PU Kota Makassar dalam melaksanakan penanganan jalan tidak sematamata karena pertimbangan kerusakan jalan, tetapi dengan pertimbangan-pertimbangan lain yang berdampak langsung bagi peningkatan sosial ekonomi masyarakat.

2. Terkait dengan implementasi penelitian ini dilapangan, maka disarankan total bobot kecamatan perlu diperiksa tiap tahun terutama untuk bobot kriteria kerusakan jalan. Hal ini berkaitan dengan persentase kondisi jalan di tiap kecamatan yang berubah dan hasil yang didapatkan tidak bias. Perubahan persentase kondisi jalan yang berubah akan merubah total bobot kecamatan.

3. Perlu memperhitungkan kriteria-kriteria lainnya untuk pengembangan penelitian ini.

\section{UCAPAN TERIMA KASIH}

Dalam pembuatan penulisan ini tentunya tidak terlepas dari campur tangan orang lain untuk itu tidak lupa kami ucapkan banyak terima kasih kepada kedua orang tua kami, istri dan anak-anak kami, terutama ibu dan bapak pembimbing dan penguji kami baik yang dikampus maupun yang diluar kampus dan mohon maaf karena tidak dapat kami urutkan namanya satu persatu, tidak lupa pula rekan-rekan di lingkungan Dinas Pekerjaan Umum Kota Makassar serta rekan-rekan adik-adik mahasiswa di kampus umi, rekan-rekan di proyek Penanganan Rutin Jalan Perkotaan, jazakallah semoga Allah Swt senantiasa selalau mengucurkan rahmat kepada kita dan membalas seluruh perhatian, dukungan serta sinergitas kita yang telah dibina selama proses penulisan ini berlangsung hingga kami dapat menyelesaikan tesis ini hingga tuntas. Wassalam.

\section{DAFTAR PUSTAKA}

Anonim, 1990, Kepmen PU Nomor 77/KPTS/Db/1990 Tentang Perencanaan dan Penyusunan Program Jalan Kabupaten. Jakarta.

Anonim, 1992, Undang-Undang Republik Indonesia No. 14 tahun 1992 tentang lalu lintas dan Angkutan Jalan.

Anonim, 1993, Peraturan Pemerintah No. 43 tahun 1993 Tentang Prasarana dan Lalu Lintas Jalan

Anonim, 1999, Undang-undang Republik Indonesia No. 22 Tahun 1999 tentang Pemerintah Daerah.

Anonim, 2000, Peraturan Pemerintah Nomor 25 Tahun 2000 tentang Kewenangan Pemerintahan dan Kewenangan Propinsi sebagai Daerah Otonomi PT. Cipta Umbara Bandung.

Anonim, 2001, Kepmen Kimpraswil Nomor 534/KPTS/M/2001. Pedoman Penentuan Standar Minimal (SPM). Jakarta.

Anonim, 2004, Undang-undang Republik Indonesia No. 38 Tahun 2004 tentang jalan.

Anonim, 2006, Peraturan Pemerintah Nomor 34 Tahun 2006 tentang jalan.

Adisasmita, R. 2005. Ekonomi Transportasi, buku ajar untuk mahasiswa program Pascasarjana Universitas Hasanuddin. Makassar.

. 2007. Pembangunan Kawasan dan Tata Ruang, buku ajar untuk mahasiswa program Pascasarjana Universitas Hasanuddin. Makassar.

. 2002. Konsep Pengembangan Sistem Wilayah di Era Otonomi Daerah. Materi kuliah Perencanaan Prasarana Transportasi. Pasca Sarjana Universitas Hasanuddin. Makassar.

Arsyad, M.A. 2005. Analisis Penentuan Prioritas Penanganan Jalan di Kecamatan Rumbia Kabupaten Jeneponto. Thesis Program Pasca Sarjana Universitas Hasanuddin Makassar.

Jayadinata, J.T. 1986, Tata Guna Dalam Perencanaan Pedesaan, Perkotaan dan Wilayah, ITB Bandung.

Jany, 2008. Penentuan prioritas penanganan jalan di Kecamatan Mandonga Kota Kendari. Thesis Program Pasca Sarjana Universitas Hasanuddin Makassar. 
Jinca, M.Y.2002, Perencanaan Transportasi. Modul perkuliahan Program Magister Perencanaan Prasarana Kerjasama Fakultas Teknik Universitas Hasanuddin Makassar dengan Pusdiktek BPSDM Departemen Kimpraswil.

Marimin. 2004. Teknik dan Aplikasi Pengambilan Keputusan Kriteria Majemuk. PT. Grasindo. Jakarta.

Morlok, E.K. 1995. Pengantar Teknik dan Perencanaan Transportasi. Erlangga. Jakarta.

Rosilawaty, 2007. Kajian prioritas perbaikan jalan di Kecamatan Tinggi Moncong Kabupaten Gowa. Thesis Program Pasca Sarjana Universitas Hasanuddin Makassar.

Saaty. TL and Vargas. LG. 1994. Decision Making in Economic, Political, Social and Technological Environments with Analytical Hierarchy Process. University of Pittsburgh.

Saaty, T,L. 1993. Pengambilan Keputusan Bagi para Pemimpin, Proses Hirarki-Analitik untuk pengambilan, keputusan dalam situasi yang kompleks. PT. Pustaka Binaman Pressindo. Jakarta.

Santoso, G. 2005. Metodologi Penelitian, Kuantitatif dan Kualitatif. Prestasi Pustaka. Jakarta.

Sihaloho, A. 2004, Strategi dan Prioritas Pengembangan Prasarana Jalan Da/am Rangka Mendukung Kapet Seram. Thesis Program Pasca Sarjana Universitas Hasanuddin Makassar.

Sugiyono, 2007, Statistika Untuk Penelitian. CV. Alfabeta. Bandung.

Suwardjoko Warpani. 1980, Analisa Kota dan Daerah. Penerbit ITB, Bandung.

Tamin, O.Z, 2000. Perencanaan dan Permodelan Transportasi. ITB. Bandung. 